\title{
Professoras iniciantes em grupo colaborativo: contributos da reflexão ao ensino de geometria ${ }^{1}$
}

\author{
Título Beginning teachers in a collaborative group: \\ Reflextion inputs for teaching geometry
}

\author{
Klinger Teodoro Ciríaco ${ }^{2}$ \\ Maria Raquel Miotto Morelatti ${ }^{3}$ \\ João Pedro da Ponte 4
}

\begin{abstract}
Resumo
Neste artigo, analisamos em que medida interações em um grupo colaborativo, constituído por professoras iniciantes, contribui para a aprendizagem da docência em Matemática. A metodologia inscreve-se no campo dos estudos qualitativos de cariz colaborativo. Tomamos por base dois episódios de vídeos de aulas de Matemática envolvendo a classificação de formas geométricas na Educação Infantil e nos anos iniciais do Ensino Fundamental. Analisamos as interações ocorridas no grupo e descrevemos como a reflexão sobre a prática docente e o compartilhamento de experiências contribuem para desenvolvimento do conhecimento das professoras. Os resultados mostram que a vivência colaborativa oportunizou a identificação de lacunas conceituais decorrentes da formação inicial das professoras e desencadeou questões no âmbito da colaboração que levaram o grupo a formular princípios pertinentes para a abordagem deste tema em suas próximas aulas.
\end{abstract}

Palavras-chave: Iniciação à Docência; Ensino de Geometria; Reflexão sobre a Prática.

\footnotetext{
${ }^{1}$ Este trabalho tem por base parte de uma pesquisa de doutorado desenvolvida pelo primeiro autor (Ciríaco, 2016) junto ao Programa de Pós-Graduação em Educação da Faculdade de Ciências e Tecnologia da Universidade Estadual Paulista 'Júlio de Mesquita Filho' FCT/UNESP, tendo como orientadora a segunda autora e como colaborador externo o terceiro autor, decorrente de um estágio de pesquisa (bolsa sanduíche) junto à Universidade de Lisboa.

2 Doutor em Educação (Educação Matemática) pela Universidade Estadual Paulista 'Júlio de Mesquita Filho' FCT/UNESP, Presidente Prudente. Professor Adjunto do Curso de Pedagogia da Fundação Universidade Federal de Mato Grosso do Sul - UFMS, Câmpus Naviraí, Brasil. E-mail: klingerufms @ hotmail.com

${ }^{3}$ Doutora em Educação (Currículo) pela Pontifícia Universidade Católica de São Paulo (PUC/SP); Professora Assistente do Departamento de Matemática e Computação (DCM) da Universidade Estadual Paulista 'Júlio de Mesquita Filho' - FCT/UNESP, Presidente Prudente. Atualmente é professora permanente e vice-coordenadora do Programa de Pós-Graduação em Educação da FCT/UNESP, Brasil. E-mail: mariaraquelmm@ gmail.com

${ }^{4}$ Doutor em Mathematics Education na University of Georgia, EUA e Professor do Instituto de Educação da Universidade de Lisboa, Portugal. E-mail: jpponte@ie.ulisboa.pt.
} 
http://periodicos.sbu.unicamp.br/ojs/index.php/zetetike

\begin{abstract}
This article analyzes the degree to which interactions in a collaborative group, consisting of beginning teachers, contributes to the teaching of learning in mathematics. The methodology is inserted at the field of qualitative study of collaborative nature. It was based on two episodes of videos of mathematics classes approaching the classification of geometrical forms for children education and at the first levels of Elementary School. The interaction developed at the group was analyzed and we described how the reflection about the teaching practice and the exchanging of experiences contribute to the development of the teacher's knowledge. The result show that the collaborative experience made it possible the identification of conceptual gaps resulting from the preservice teacher education program, and it unleashed issues at the scope of collaboration, what led the group to formulate pertinent principles for the approaching of this topic in their next classes.
\end{abstract}

Keywords: Beginning teaching; Geometry teaching; Reflection on the Practice.

\title{
Introdução
}

O início da docência constitui uma das principais fases do desenvolvimento profissional dos professores que ensinam Matemática. A formação inicial proporcionou a estes professores muitos conhecimentos, capacidades e perspectivas de ação para a sua atividade docente, mas também deixou lacunas e debilidades relativamente a muitos aspetos da atividade docente. O início da vida profissional levanta fortes desafios ao jovem professor, sendo importante perceber como este os enfrenta e que contributos podem esperar do suporte de um trabalho colaborativo organizado especificamente para esse fim. Neste tipo de trabalho, a reflexão pode tornar-se a base para as ações, permitindo aos professores iniciantes amenizar suas dificuldades no processo de aprender a ensinar, e essa vivência poderá ajudar a superar a dicotomia conhecimento matemático/conhecimento didático, muito presente nos cursos de licenciatura no Brasil.

Assim, esse trabalho tem como objetivo compreender em que medida interações no seio de um grupo colaborativo de professoras iniciantes contribui para a aprendizagem da docência em Matemática. Centramos a discussão nas contribuições da reflexão sobre a prática docente por parte dos membros do grupo constituído por quatro professoras com formação em Pedagogia, uma professora especialista egressa do curso de licenciatura em Matemática e pelo primeiro autor deste artigo. Procuramos destacar elementos que caracterizam o processo de ensino e aprendizagem, nesse caso de Geometria, como objeto da formação das professoras iniciantes a partir do compartilhamento de suas experiências.

\section{Enquadramento teórico \\ Conhecimento matemático e didático do professor e os primeiros anos da carreira}

Ponte e Chapman (2008) consideram que o conhecimento do professor para ensinar Matemática pode ser analisado sob dois campos primordiais: o conhecimento matemático para o ensino e o conhecimento didático. $\mathrm{O}$ conhecimento matemático para o ensino pode ser compreendido como o conhecimento específico para ensinar, que difere do conhecimento matemático de outras áreas (Branco, 2013). Esse conhecimento exige do professor uma profunda compreensão da Matemática para que possa auxiliar seus alunos a compreenderem 
http://periodicos.sbu.unicamp.br/ojs/index.php/zetetike

os conceitos e propriedades matemáticas. Branco (2013, p. 75) afirma que esse conhecimento "deve contribuir para a melhoria do desempenho dos alunos, envolvendo esse trabalho de ensinar aspetos como a explicação de termos e conceitos aos alunos, a interpretação das resoluções e conclusões, o uso das representações na sala de aula", como também a análise da abordagem em tópicos específicos de ensino. Na formação inicial, os futuros professores precisam ter oportunidades para desenvolverem esse conhecimento para preparar suas futuras práticas, ou seja, necessitam aprender Matemática para que possam ter êxito na tarefa de ensinar.

O conhecimento didático, por sua vez, refere-se ao conjunto de saberes que orientam a atuação do professor em situações de ensino de um determinado conteúdo. Ele está presente desde o planejamento das aulas até a efetivação da prática letiva.

O conhecimento do ensino da Matemática engloba, nomeadamente, o conhecimento dos objetivos gerais do ensino da Matemática, da natureza das tarefas e de recursos para utilizar na sala de aula, dos modos de trabalho na sala de aula, da comunicação matemática na sala de aula e da avaliação, dando atenção ao pensamento dos alunos e aos processos de aprendizagem (Branco, 2013, p. 77)

Nos cursos de licenciatura em Pedagogia, o espaço usual de formação inicial de professores para a Educação Infantil e os anos iniciais do Ensino Fundamental, o conhecimento matemático oportunizado ao futuro professor tem-se mostrado insuficiente, superficial e fragmentado (Curi, 2004). Isso revela a fragilidade da formação conceitual em Matemática para ensino dos conteúdos elencados para esses segmentos de atuação do pedagogo na escola. Já nos cursos de licenciatura em Matemática parece acontecer o oposto: privilegia-se o conhecimento do conteúdo matemático em detrimento da formação didáticopedagógica, deixando implícita a ideia de que basta ter conhecimento matemático para saber ensiná-lo (Fiorentini e Oliveira, 2013).

Para os cursos de Licenciatura, o Parecer 1302 das Diretrizes Curriculares (Brasil, 2001) destaca que a grade curricular precisa conter: Cálculo Diferencial e Integral, de Análise Matemática, de Álgebra, de Geometria, de Estatística, de Combinatória, de Probabilidade, entre outros. Curi (2011, p. 88) designa estes temas como os "chamados conhecimentos substantivos do futuro professor", considerando que no curso "há um grande número de horas destinadas à formação matemática”. O referido Parecer destaca ainda que a formação do licenciado em Matemática necessita prever na base comum "conteúdos matemáticos presentes na educação básica nas áreas de Álgebra, Geometria e Análise” (p. 06). No entanto, as diretrizes oficiais são omissas em relação aos referenciais teórico-metodológicos sobre o ensino da Matemática.

Ponte e Chapman (2008) consideram que tanto o conhecimento matemático quando o didático precisam se apresentar de maneira integrada na formação inicial. Contudo, observamos uma realidade formativa em ambos os perfis de formação inicial de professores em que estes estão fortemente dissociados, o que contribui significativamente para dificuldades de abordagem dos conteúdos no momento da inserção na docência. 
http://periodicos.sbu.unicamp.br/ojs/index.php/zetetike

Para Fiorentini e Oliveira (2013), o problema da formação inicial não consiste apenas na dissociação entre o conhecimento matemático e o didático, mas também da dissociação destes com os conhecimentos das práticas de ensinar e aprender matemática nas escolas. Defendem que os conhecimentos e casos de ensino da prática do professor que ensina matemática também sejam tomados como objeto de estudo e problematização durante o curso de licenciatura.

Guarnieri (1996) afirma que o exercício da profissão docente se consolida no processo de se tornar professor. Em outras palavras, para a autora, "o aprendizado da profissão a partir de seu exercício possibilita configurar como vai sendo constituído o processo de aprender a ensinar" (p. 5). Segundo Nono (2011), o início da carreira trata-se de "um período de sobrevivência e descoberta em que os professores procuram ajustar suas expectativas e ideias sobre a profissão às condições reais de trabalho que encontram" (p. 6). Dessa maneira, o ingresso na docência precisa ser encarado como uma importante fase do "desenvolvimento profissional, na medida em que se pretende, [através de programas] que os professores adquiram conhecimentos, [competências e atitudes] adequadas ao desenvolvimento de um ensino de qualidade" (Marcelo García, 1999, p. 65). Para isso consideramos importante um movimento na formação de professores que seja organizado na perspectiva do desenvolvimento profissional, ou seja, uma mudança que se preocupe com compreensão da dinâmica do trabalho docente e sua complexidade.

\section{A reflexão sobre a prática como possibilidade de desenvolvimento profissional}

A reflexão sobre a ação docente é um ponto importante para que o professor possa pensar sua prática num contexto real, ou seja, em ação, pois a formação inicial não oportuniza um pensar sistemático sobre a atuação profissional, muito menos da gestão de classe. Contudo, projetos como o Programa Institucional de Bolsas de Iniciação à Docência (PIBID) e o espaço formativo do estágio obrigatório, poderiam trazer contribuições importantes, mesmo que limitadas, para o conhecimento do aprender a ensinar.

Compreender o ensino como objeto principal do profissional professor implica, como aponta Moura (2001), entender a organização dos princípios norteadores de suas ações para que ele, cada vez mais, organize o ensino como um fazer que se aprimora ao fazer, na medida em que se torna objeto de reflexão.

De acordo com Freire (1996), isto significa que é preciso possibilitar o movimento de voltar-se a si mesmo, por meio da reflexão sobre a prática, tornando-se, assim, um educador crítico. Por isso, na formação permanente dos professores, um dos movimentos fundamentais é o da reflexão crítica sobre a prática:

O que importa, na formação docente, não é a repetição mecânica do gesto, este ou aquele, mas a compreensão do valor dos sentimentos, das emoções, do desejo, da insegurança a ser superada pela segurança, do medo que, ao ser "educado", vai ganhando coragem (Freire, 1996, p. 26). 
http://periodicos.sbu.unicamp.br/ojs/index.php/zetetike

Portanto, conceber uma prática educativa nesse contexto é ultrapassar a esfera da racionalidade técnica, implica mudança de atitude apoiada em senso crítico e ético. Nessa concepção, para ser professor é necessária uma ação que vise transformar-se ao transformar o outro, mudar o seu modo de ser e de agir. Tomamos em atenção, além disso, que o professor não vive isolado, necessita da interação entre os pares, das trocas, do fazer coletivo que dá sustentação à mudança na prática pedagógica condizente à realidade.

A partir desse entendimento, temos, na base reflexiva, uma possibilidade rica e promissora que, quando explorada de forma adequada, pode resultar no desenvolvimento profissional docente em contextos de formação permanente. Assim, valorizamos os três momentos da reflexão sobre a ação, especificados por Schön (1992), a reflexão na ação, sobre a ação sobre a reflexão na ação.

A reflexão na ação ocorre quando o professor nota algo inusitado durante as ações de sua prática em sala de aula e reformula seus conhecimentos, ajustando-se aos desafios e situações adversas que aparecem. Na reflexão sobre a ação o professor, ao reconstruir sua ação mentalmente, começa a analisar passo a passo o desenvolvimento de seu trabalho. A prática reflexiva aqui está centrada no caráter posteriori da ação, ou seja, o olhar para a prática com vistas a verificar o que ocorreu que medidas foram tomadas para resolver os impasses que aconteceram. A reflexão sobre a reflexão-na-ação fomenta a evolução e o desenvolvimento profissional na medida em que leva o professor a formar próprias maneiras de conhecer a si mesmo. Nesse processo, estão presentes ações de metareflexão ao desenvolver novos raciocínios, formas de pensamento, compreensão, ação para solução dos problemas da carreira docente, ou seja, o professor é levado a pensar sobre o modo como refletiu em suas ações.

\section{Metodologia de investigação}

A abordagem metodológica adotada se inscreve no campo da pesquisa qualitativa em educação (Bogdan \& Biklen, 1994) tendo por base o contato direto do primeiro autor (designado doravante por "formador-pesquisador") no ambiente de um grupo de trabalho colaborativo. Para tal, recorremos a dados provenientes de reflexões sobre a prática pedagógica de quatro pedagogas e uma professora de Matemática, coletados em encontros ocorridos quinzenalmente no período de agosto de 2013 a julho de 2015. As professoras participantes tinham entre cinco meses e três anos de experiência profissional. Durante a realização do trabalho de campo estavam em atuação em escolas públicas da rede municipal e/ou estadual de Naviraí, no interior do estado de Mato Grosso do Sul, e no sistema privado de ensino. Todas são egressas de cursos de Pedagogia e Matemática de instituições locais ou próximas ao município de Naviraí. Alice e Sofia possuem licenciatura em Pedagogia pela Universidade Federal de Mato Grosso do Sul, UFMS, sendo ex-alunas do formadorpesquisador. Stella e Paula são egressas do curso de Pedagogia das Faculdades Integradas de Naviraí - FINAV - e Bianca graduou-se no curso de licenciatura em Matemática da Universidade Estadual de Mato Grosso do Sul (UEMS). 
http://periodicos.sbu.unicamp.br/ojs/index.php/zetetike

O trabalho de pesquisa decorreu a partir de um planejamento de atividades colaborativas elaborado inicialmente pelo formador-pesquisador com base nos objetivos do estudo, tendo como pressuposto essencial a possibilidade de transformação da realidade educacional com base na cultura de colaboração (Fullan \& Hargreaves, 2000). No que respeita à dinâmica das reuniões, procurou-se promover discussões dos problemas vivenciados nas aulas com o objetivo de construir formas de superação a partir da prática dialógica da colaboração.

Ao todo, realizaram-se 39 sessões de discussão com as professoras. As temáticas abordadas destinaram a atender suas necessidades tanto formativas quanto de planejamento das aulas que ministravam em cada momento do ano letivo. Dentre os assuntos, emergiram reflexões sobre o conhecimento matemático para o ensino e o conhecimento didático sobre números e sistema de numeração decimal, estruturas aditivas, estruturas multiplicativas, expressões numéricas, Geometria, tratamento da informação, equações, entre outros temas.

O papel do formador-pesquisador foi o de "cienticizar" (Franco, 2005) as mudanças, atitudes e tomadas de decisões mediante a aprendizagem da docência nos primeiros anos da carreira das integrantes.

O "cienticizar", papel assumido pelo formador-pesquisador, esteve presente numa perspectiva de intervenção pedagógica ao longo das discussões sobre a aprendizagem matemática e os recursos para o ensino. Isso porque o itinerário de vida acadêmicoprofissional decorrente da experiência como professor da Educação Básica e do Ensino Superior, possibilitou ampliar a visão do grupo sobre as recomendações da Educação Matemática e da sua própria visão em relação aos procedimentos de ensino adotados pelas professoras ao relatarem suas práticas docentes.

As reflexões suscitadas do ponto de vista teórico e as suas articulações com a prática escolar foram possíveis em decorrência das leituras do formador-pesquisador sobre formação. Assim, no espaço das reuniões, sempre que surgiam dúvidas conceituais e/ou pedagógicas quanto aos procedimentos de ensino, o formador-pesquisador elaborava sínteses no quadronegro (lousa) e apresentava considerações de autores sobre o conhecimento didático relativo ao ensino em sala de aula.

O envolvimento das professoras foi para além do espaço do grupo. Elas gravaram suas aulas, com o auxílio dos alunos, as quais passaram a ser objeto de reflexão inicialmente pessoal e, posteriormente, coletiva, sobretudo quando traziam os vídeos das aulas para discussão no grupo. O objetivo dessa dinâmica de trabalho era problematizar suas práticas, sendo esta uma forma de melhoria do ensino.

A importância do vídeo para a aprendizagem profissional de Sofia foi marcante ao longo do processo formativo, pois abriu espaço para refletir sobre si e sua prática.

Em decorrência das discussões das aulas de Sofia, as demais professoras também começaram, aos poucos, a gravar pequenos fragmentos de suas aulas, trazendo-os para discussão nas reuniões do grupo. Essa ação, embora desenvolvida num espírito embrionário, 
http://periodicos.sbu.unicamp.br/ojs/index.php/zetetike

apresentou-se para nós, mesmo não sendo diretamente uma fonte de coleta de dados deste estudo, uma possibilidade de compreender melhor como as professoras introduziam, desenvolviam e concluíam a abordagem dos conteúdos matemáticos.

Consideramos que esse movimento autônomo das professoras, decorrente da gravação de trechos das suas aulas, aproxima-se do que Schön (1992) tem denominado de reflexão-naação, reflexão-sobre-a-ação e de reflexão sobre a reflexão-na-ação.

A experiência de assistir ao vídeo possibilitou aprofundar a reflexão sobre a abordagem dos conteúdos matemáticos. Graças à iniciativa das próprias integrantes do grupo de gravar episódios relativos às suas práticas pedagógicas em Matemática, pudemos obter um rico material de análise, envolvendo cenas de aulas relativas ao ensino e aprendizagem de geometria. Para análise, neste artigo, selecionamos dois episódios onde procuramos compreender as características das tarefas propostas pelas docentes e seus discursos perante as explicações do conteúdo na perspectiva de contribuir com o processo de aprender a ensinar. Em termos mais gerais, a análise dos episódios, a seguir, coloca em destaque a vivência da colaboração e principalmente as aprendizagens ocorridas nos encontros e que serviram de mote para o desenvolvimento do conhecimento matemático e didático das professoras iniciantes.

\section{Análise e reflexão sobre as aulas de Alice e Sofia}

Os vídeos compartilhados por Alice e Sofia trazem episódios de aulas sobre ensino de geometria e que tinham por objetivo classificar formas geométricas. Embora as duas atuassem em níveis de ensino diferentes - Alice na Educação Infantil e Sofia nos anos iniciais do Ensino Fundamental -, foi possível analisar e refletir sobre a importância de uma atuação mais condizente com as perspectivas da Educação Matemática, destacando as primeiras aprendizagens e a formação do pensamento geométrico das crianças, a partir de uma abordagem exploratória.

O Quadro 1, a seguir, resume o cenário da aula de Alice.

Quadro 1 - Descrição dos aspectos do vídeo da aula de Alice compartilhado com o grupo

\begin{tabular}{|c|c|c|c|}
\hline $\begin{array}{l}\text { Introdução do } \\
\text { conteúdo }\end{array}$ & $\begin{array}{c}\text { Recurso/materiais } \\
\text { utilizados }\end{array}$ & Desenvolvimento/dinâmica da aula & Avaliação \\
\hline $\begin{array}{l}\text { Realizada } \\
\text { oralmente por } \\
\text { meio de } \\
\text { conversa com as } \\
\text { crianças sobre } \\
\text { as formas } \\
\text { geométricas, } \\
\text { envolvendo as } \\
\text { cores azul, } \\
\text { amarelo, } \\
\text { vermelho e }\end{array}$ & $\begin{array}{l}\text { a) Cartaz em papel } \\
\text { manilha contendo } \\
\text { figuras de } \\
\text { triângulos, } \\
\text { retângulos, } \\
\text { quadrados } \\
\text { círculos coloridos; } \\
\text { b) Fitas amarelas } \\
\text { amarradas nos } \\
\text { pulsos e pés direitos } \\
\text { das crianças. }\end{array}$ & $\begin{array}{l}\text { A professora coloca o cartaz com as } \\
\text { formas no chão, ao centro da sala em um } \\
\text { tatame, e convida as crianças, } \\
\text { individualmente, à participação na tarefa. } \\
\text { Em seguida, solicita que coloquem a mão } \\
\text { direita (distinguida pela fita amarela no } \\
\text { pulso) em uma forma geométrica contida } \\
\text { no cartaz e, posteriormente, repete a } \\
\text { ação, só que dessa vez pede que a criança } \\
\text { coloque o pé na figura. Essa sequência é } \\
\text { repetida com todas. }\end{array}$ & $\begin{array}{lr}\text { Realizada de } & \text { forma } \\
\text { coletiva com base } & \text { na } \\
\text { observação } & \text { da } \\
\text { participação } & \text { das } \\
\text { crianças } & \text { no } \\
\text { desenvolvimento } & \text { da } \\
\text { tarefa proposta. } & \end{array}$ \\
\hline
\end{tabular}


http://periodicos.sbu.unicamp.br/ojs/index.php/zetetike

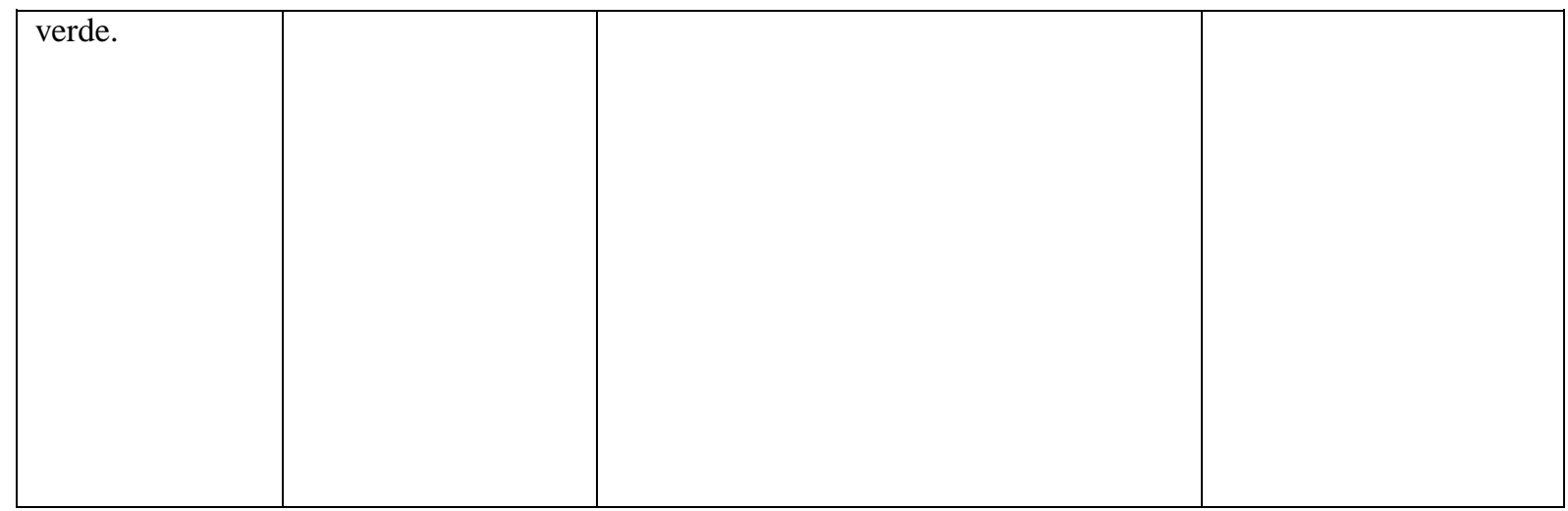

Fonte: Ciríaco (2016)

Durante o compartilhamento dessa experiência, em uma turma de maternal ${ }^{5}$, Alice assistiu ao vídeo junto às demais docentes. Em seu discurso, revelou o quanto a prática de gravar e ver sua aula possibilitou-lhe fazer uma reflexão diferente daquela baseada apenas no discurso do processo vivido, ou seja, destacou a relevância do vídeo como objeto de análise de sua própria atuação profissional:

A experiência de gravar está sendo boa. Estou querendo até gravar uma aula no Ensino Fundamental I, porque, como nós relatamos no grupo, foi um modo de nos avaliarmos. Eu vi meu Deus quanta coisa errada eu fiz - e te bate um peso na consciência que, lá na hora com a criança, você não percebe os seus erros ou se você falou de algum jeito que não deveria ter falado. Então, eu estou só esperando desafogar essa semana, que está acabando o bimestre, para gravar uma aula [...] Através da gravação da aula pude ver os pontos negativos e positivos, saber no que eu posso melhorar e o que eu tenho que continuar (Professora Alice).

No final da apresentação do vídeo da aula, foi aberto um espaço para discussão das demais professoras do grupo, momento em que Bianca, Paula, Sofia e Stella puderam dar os seus contributos a partir de suas vivências em aulas com o mesmo conteúdo. Alguns aspectos problematizados pelas professoras, com a ajuda da intervenção do formador-pesquisador, referiram-se a:

(a) Classificação de formas geométricas associadas a cores;

(b) Conhecimento físico, social e lógico-matemático; e

(c) Referência adotada para a tarefa proposta.

Forma e cor. Em relação à associação feita entre cor e forma, identificamos que, a partir da vivência inicial das crianças, não é possível afirmar que essa prática de Alice tenha garantido uma aprendizagem e, muito menos, permitido uma experiência de formação do pensamento geométrico. A intervenção do formador-pesquisador permitiu que o grupo tomasse conhecimento de alguns aspectos cognitivos relativos à aprendizagem nessa fase da vida escolar. Tendo por base leituras de Kamii (1990), sob uma perspectiva piagetiana, o formador-pesquisador problematizou e mediou a intervenção discutindo que a natureza do conhecimento tem suas raízes em três bases de estruturação: conhecimento físico;

\footnotetext{
${ }^{5}$ Crianças de 3 anos.
} 
http://periodicos.sbu.unicamp.br/ojs/index.php/zetetike

conhecimento social; e conhecimento lógico-matemático (Kamii, 1990). A ênfase dada por Alice, na atividade desenvolvida, caminhou de forma atrelada ao conhecimento físico, ou seja, pertencente às características físicas dos objetos, nesse caso, a cor das formas geométricas apresentadas.

A intervenção do formador-pesquisador foi realizada com o objetivo de demonstrar que a professora, na organização da atividade educativa, deu origem a um equívoco ao mostrar as formas geométricas associadas a uma cor específica, nomeadamente os círculos azuis, triângulos amarelos, quadrados vermelhos e retângulos verdes. Ou seja, o problema não é a cor, mas a distinção feita que classificou uma forma com referência a uma única cor. Em outras palavras, a reflexão do grupo permitiu fazer com que as professoras compreendessem que um trabalho com as noções geométricas, no âmbito da Educação Infantil, precisa favorecer a exploração da criança em relação aos objetos ou às formas. Desse modo, Alice teria mais êxito na atividade se a organizasse de modo que a mesma figura tivesse cores diferentes, pois assim oportunizaria às crianças uma classificação a partir dos atributos definidores da figura e não pela cor. Nesse caso, a referência não seria a cor, mas sim a forma, pois à medida que a criança explorasse o jogo teria maiores oportunidades de perceber que, independente da cor, os atributos definidores da figura seriam os mesmos. Esse viés seria um caminho para explorar o conhecimento lógico-matemático em que a criança poderia atribuir relações entre uma forma e outra ao perceber diferenças e semelhanças com base nas características da forma da figura. Na sequência, Alice poderia nomear as figuras, apresentando o conhecimento social, a forma como estas são classificadas em Matemática através dos respectivos nomes (triângulo, quadrado, retângulo e círculo).

O grupo também conseguiu ampliar a discussão destacando que, ao associar uma forma geométrica a uma cor, a atitude da criança, do ponto de vista da aprendizagem, pode ser a de "decorar" a cor e, com isso, toda vez que encontrar uma figura azul tende a categorizá-la como sendo um círculo, por exemplo. Ao refletir sobre a prática dessa professora, chegamos a uma conclusão de que muitos dos problemas em relação à organização e ao desenvolvimento da proposta estão atrelados também à falta de especificidade e conhecimento de conteúdo dos professores em início de carreira.

Por outro lado, o discurso de Alice, no direcionamento das ações das crianças durante a aula, foi avaliado por todas as professoras do grupo como apropriado uma vez que a professora conduziu uma prática dialógica pautada em questionamentos das ações de seus alunos. Além disso, foi também possível observar outro aspecto positivo durante a atividade e que diz respeito ao fato de o ensino ser centrado na criança e não na figura do professor, o que favoreceu a participação ativa na aula, conforme evidenciou o vídeo.

Pontos de referência. O direcionamento das ações em sua interação com as crianças permitiu que a professora atingisse um dos objetivos para o trabalho com a Geometria na Educação Infantil descrito nos Referenciais Curriculares Nacionais (Brasil, 1998, p. 229), nomeadamente a "identificação de pontos de referência para situar-se e deslocar-se no espaço", uma vez que, ao chamar as crianças ao centro da sala de aula e solicitar que 
http://periodicos.sbu.unicamp.br/ojs/index.php/zetetike

posicionassem o pé e/ou a mão direita em cima de determinada figura geométrica, Alice articula pensamentos relacionados à Geometria espacial, características essa de grande valia para a formação do pensamento geométrico na infância. Nessa perspectiva, a criança utiliza seu próprio corpo como ponto de referência para a construção do espaço, desenvolvendo, com isso, noções geométricas.

Por esse motivo, é recomendável que o professor proponha atividades que articulem o espaço vivido pela criança sob o ponto de vista corporal. Nesse contexto, a contribuição do professor, as interações entre as crianças, jogos e brincadeiras podem propiciar a exploração espacial em três perspectivas: (a) relações espaciais contidas nos objetos; (b) relações espaciais entre os objetos, e (c) relações espaciais nos deslocamentos (Brasil, 1998).

Destacamos nas reflexões do grupo de professoras iniciantes que o trabalho em Geometria com crianças pequenas precisa incorporar contextos que se referem às relações que a criança estabelece, habitualmente, com o espaço, tais como "construir, deslocar-se, desenhar etc., e à comunicação dessas ações” (Brasil, 1998, p. 230), características estas evidenciadas na aula de Alice como pontos fortes de suas ações.

Além das questões da aula compartilhada, o movimento de explorar formas de trabalho com a geometria na Educação Infantil levou ao reconhecimento de limitações decorrentes da falta de conhecimento por parte de todas as professoras, inclusive de Bianca, professora de Matemática, que se sensibilizou com as pedagogas e mencionou ser natural isso porque

não temos base sobre geometria na formação inicial, eu mesma tenho sempre que recordar ou retomar o estudo para classificar as formas, são muitos conteúdos e tem coisa que aprendemos na faculdade que nem utilizamos, enfim... Acho que nem eu saberia como proceder na Educação Infantil, é muito complexo trabalhar isso com crianças pequenas! (Professora Bianca).

Sobre essas questões, evidencia-se que, em relação ao ensino de geometria, as docentes apresentaram algumas características mais direcionadas ao conhecimento didático do conteúdo (Ponte \& Chapman, 2008), componente este que, ao que tudo indica, parece ser um aspecto mais presente nos cursos de formação inicial das professoras, pois Bianca menciona que, mesmo na licenciatura em Matemática, o conhecimento do conteúdo da matemática escolar é algo pouco trabalhado.

Chamamos à atenção para o fato de que deveria ser papel da formação inicial integrar, de acordo com Branco e Ponte (2011, p. 04), “o conhecimento dos conteúdos e processos matemáticos, a especificidade dos alunos a ensinar, de acordo com a sua escolaridade, e as orientações curriculares". Esse conhecimento precisaria ser desenvolvido "integrando conteúdos e pedagogia e ensinando os futuros professores do mesmo modo que se espera que eles ensinem a seus alunos" (Ponte \& Chapman, 2008, p. 256).

Ao reconhecermos alguns elementos estruturantes da aula e verificarmos pontos que poderiam ser melhorados em ações futuras pelas professoras, o formador-pesquisador fez 
http://periodicos.sbu.unicamp.br/ojs/index.php/zetetike

inferências ${ }^{6}$ sobre o quanto a aula apresentada no grupo permitiu observar a interação da criança com a tarefa e que, a partir dessa reflexão, o grupo pode, em aulas futuras com conteúdos da mesma área, tentar trabalhar com ênfase em discursos que favoreçam a participação da criança, como verificado na experiência da Educação Infantil.

Sobre a aula de Sofia, também direcionada ao bloco de conteúdos "Espaço e forma", foi desenvolvida em uma turma de $4 .^{\circ}$ ano do Ensino Fundamental de uma escola da rede particular e apresentou-se com as características descritas no quadro 2:

Quadro 2 - Descrição dos aspectos do vídeo da aula de Sofia compartilhado no grupo

\begin{tabular}{|c|c|c|c|}
\hline $\begin{array}{l}\text { Introdução do } \\
\text { conteúdo }\end{array}$ & $\begin{array}{l}\text { Recursos/mate- } \\
\text { riais utilizados }\end{array}$ & Desenvolvimento/dinâmica da aula & Avaliação \\
\hline $\begin{array}{l}\text { Brincadeira na quadra } \\
\text { da escola que } \\
\text { consistia em agregar } \\
\text { pontuação a partir do } \\
\text { lançamento de um } \\
\text { pino em um desenho } \\
\text { de uma representação } \\
\text { de sólido geométrico } \\
\text { feita com giz no } \\
\text { chão. }\end{array}$ & $\begin{array}{l}\text { a) Brincadeira na } \\
\text { quadra; } \\
\text { b) Explicações } \\
\text { orais com a } \\
\text { utilização da lousa } \\
\text { em sala de aula. }\end{array}$ & $\begin{array}{l}\text { A professora introduz o reconhecimento visual } \\
\text { de alguns sólidos a partir da brincadeira na } \\
\text { quadra e faz a nomeação dos mesmos. Na } \\
\text { sequência, direciona o grupo de alunos para a } \\
\text { sala de aula onde realiza explicações orais de } \\
\text { forma mais unívoca e manipula alguns sólidos } \\
\text { para justificar os atributos definidores e } \\
\text { características dos mesmos. Por fim, finaliza a } \\
\text { proposta sem muita comunicação e diálogo } \\
\text { com seus alunos. }\end{array}$ & Não houve. \\
\hline
\end{tabular}

Fonte: Ciríaco (2016).

Antes de iniciar a apresentação do vídeo, Sofia confessou estar um pouco envergonhada. Antes de vir para a reunião resolveu assistir e não teve boas impressões do modo como agiu e, principalmente, do que seus alunos concluíram após suas explicações, uma vez que ela própria reconheceu estar confusa e "perdida" durante a aula:

O meu vídeo foi formas geométricas espaciais e eu não consegui terminar a aula no mesmo dia (...) A partir do que filmei, cheguei à minha casa, como eu não terminei o conteúdo (...) fui ver o que eu falei. Daí eu olhei assim e pensei: “gente, mas como eu falei isso?". Eu pensei assim: "eu tinha que falar tal coisa", "eu tinha que falar que forma geométrica ocupa o espaço? Será que é isso mesmo?", mas tenho a aula de amanhã ainda, então na aula de amanhã vai ser um reforço (Risos). Aí foi onde eu consegui bastante resultado positivo. Eu só pude ver isso porque eu vi o vídeo porque se não iria passar, continuaria a errar com meus alunos. Eu olhei assim e falei "faltou isso, faltou aquilo", sabe quando ficou pobre a minha apresentação? (Risos) ficou muito pobre. Aí eu falei: amanhã eu vou passar. Aí a minha apresentação foi conforme o conteúdo da minha apostila. Então primeiro eu brinquei porque eu estou seguindo as "ordens" da Paula: primeiro brinca, depois passa o conteúdo (Risos) [Depoimento de Sofia].

A manifestação preliminar da professora desencadeou uma discussão do grupo, no sentido de identificar seus objetivos, bem como o desenvolvimento da tarefa proposta. Inicialmente, observamos um ponto positivo que foi iniciar o trabalho com uma situação

\footnotetext{
${ }^{6} \mathrm{O}$ formador-pesquisador assume a narrativa como representante e em nome do grupo.
}

Zetetiké, Campinas, SP, v.24, n.2, maio/ago.2016, p.249-268 
http://periodicos.sbu.unicamp.br/ojs/index.php/zetetike

lúdica, contudo, ao final, concluímos que esta não teve um propósito claro com essa atividade, pois ao encerrar o jogo na quadra, a professora Sofia retorna à sala de aula e não estabelece conexões entre a atividade lúdica desenvolvida na quadra e a que desenvolveu, a seguir, conceitualmente em classe.

Conforme observado em seu discurso, houve tentativas de introduzir em sua prática contribuições de discussões anteriores em que compartilhamos e discutimos ideias e princípios do jogo matemático no ensino. Tal como descreve Grando (2000, p. 4), o jogo precisa ser encarado como uma atividade que tem seu potencial formativo atrelado com a intervenção direta do professor como "um fator determinante na transformação", o que não ocorreu na aula exposta. Alguns elementos do papel dos jogos nas aulas de Matemática já haviam sido explorados com as professoras iniciantes no decorrer das reuniões e os aspectos discutidos foram:

a) Quando a atividade lúdica ou o jogo é intencional, a preocupação precisa centrarse no processo de construção dos conceitos envolvidos na proposta;

b) $\mathrm{O}$ professor é um agente importante na mediação entre o jogo, aluno e o conhecimento matemático, portanto, sua intervenção com questionamentos que levem a reflexão dos procedimentos adotados pelos alunos é relevante nesse contexto;

c) É necessário planejar a forma pela qual será feita a análise do desencadeamento, organização e coordenação da atividade lúdica quando do momento da conceitualização matemática no espaço da sala de aula, ou seja, os pontos de interlocução entre jogo e conteúdo precisam ser explicitados;

d) Por fim, o jogo não pode ser, quando intencional, apenas um procedimento inicial da aula sem relação com o processo de ensino do conteúdo abordado e, por isso, precisa ser bem planejado por parte do docente.

$\mathrm{Na}$ discussão destes elementos o grupo chegou ao consenso de que a utilização dos jogos matemáticos precisa contribuir para o desenvolvimento da aula e, portanto, precisava tornar-se um elemento estruturante e contínuo do processo de aprendizagem matemática, o que exigiria uma mudança de cultura, pois a maioria das propostas das quais tinham contato supervalorizavam técnicas de memorização de regras.

Uma perspectiva de trabalho que encara o jogo como um recurso pedagógico se constitui "uma forma interessante de propor problemas, pois permitem que estes sejam apresentados de modo atrativo e favorecem a criatividade na elaboração de estratégias de resolução e busca de soluções" (Brasil, 1998, p. 47). Dessa maneira, ao discutirmos esses pontos e retomarmos nessa reunião em que Sofia e Ana apresentaram suas aulas, as professoras destacaram o entendimento de que situações de jogos podem contribuir para o desenvolvimento da aprendizagem desde que a ação seja bem planejada e que os resultados possam ser discutidos e ressignificados, como ocorreu neste encontro. 
http://periodicos.sbu.unicamp.br/ojs/index.php/zetetike

Desse modo, ao ser questionada sobre como pensou na tarefa com o jogo, Sofia respondeu:

Eu dividi a sala em três grupos, sendo que o grupo que tivesse mais pontuação ganharia, só que acabou chegando mais um aluno então isso não valeu porque quatro contra três lógico que aquele grupo ia conseguir um número maior. Desenhei primeiro todas as formas geométricas espaciais na lousa e expliquei para eles o nome de cada uma, paralelepípedo, esfera, cilindro, cubo, pirâmide, prisma, cone e coloquei um valor, cada um tinha um valor. (...) Conforme o livro que vem o conteúdo eu tive que dar a explicação de vértice, arestas, e face, como eu tenho dados eu dei um dado para todos porque com o dado é fácil de eu explicar, mas quando chegou na pirâmide a com base triangular eles já se perdiam porque são tantos lados para você contar quantas arestas tinham que eles falaram assim "eu já contei essa daqui" e na verdade não tinha contado. Eu usei bastante o material de apoio que vem pra eles montarem porque como é colorido fica mais fácil de eles marcarem a face certa, mas minha dificuldade é visível! (Professora Sofia).

Nesse momento da reflexão, o formador-pesquisador chamou à atenção das professoras para o campo de exploração do espaço da própria escola como forma de reconhecer e identificar a presença da Geometria no ambiente em que as crianças vivem, dado que numerosas recomendações tanto dos Parâmetros Curriculares Nacionais (Brasil, 1997) quanto da de autores de Educação Matemática (Gálvez, 1996; Santaló, 1996; Vasconcellos, 2005) apontam ser preciso que o ambiente escolar proporcione um estudo das relações geométricas em uma ampla interação entre a criança e o mundo em que vive. Nessa perspectiva, o fato de a professora ter iniciado a atividade no ambiente externo à sala de aula poderia ter sido melhor explorado no sentido de que essa tarefa poderia ter auxiliado os alunos a reconhecerem objetos semelhantes às formas e/ou aos sólidos geométricos no espaço em que vivem.

Outro indicativo evidente no discurso de Sofia, quando do instante de socialização na reunião, foi a forma como descreveu as explicações dadas aos alunos. Tanto no vídeo quanto em sua fala observa-se o ideário pedagógico de que, para compreender o conteúdo, bastaria mostrar as formas para a turma no sentido de apresentação visual enunciando suas propriedades e isso acarretaria uma compreensão definitiva, características estas consideradas incorretas para Pires, Curi e Campos (2000).

Panizza (2006) destaca que a geometria, ao longo do Ensino Fundamental, parece ter dois objetivos centrais. O primeiro diz respeito à possibilidade de construção de relações geométricas que foram elaboradas ao longo da história do acúmulo do conhecimento da humanidade e de seus esforços para demarcarem o espaço. O segundo é "[...] a iniciação de um modo de pensar próprio do saber geométrico" (Panizza, 2006, p. 175).

Complementando esses pressupostos, cumpre salientar que o foco da abordagem dessa área nos anos iniciais precisa contribuir com o conhecimento teórico dos alunos e, para que isso ocorra, é necessário "tanto o recurso às bases intuitivas quanto aquele dirigido à atividade experimental, devendo ambos serem considerados pelo professor" (Nacarato; 
http://periodicos.sbu.unicamp.br/ojs/index.php/zetetike

Passos, 2003, p. 41). A partir dessa compreensão, o trabalho inicial de Sofia poderia ter envolvido seus alunos em atividades que favorecessem "a observação, a manipulação e a exploração de diferentes objetos do cotidiano" (Vasconcellos, 2005, p. 14), uma vez que as orientações para o ensino dessa área do conhecimento, nos anos iniciais, têm explicitado alguns exemplos dessa natureza. Contudo, a reflexão sobre esses aspectos no ambiente do trabalho coletivo desencadeou um movimento de reconhecimento, por parte das professoras iniciantes, da falta de conhecimento sobre geometria para poder ensinar os alunos, isso desde a Educação Infantil, como vimos na aula de Alice.

Diferentemente da tarefa de Alice, Sofia teve um planejamento centrado na figura do professor. Essa constatação foi unânime no grupo e a própria professora o reconheceu, pois ao afirmar que pelo fato ter pouca experiência em termos de trabalho com a Geometria nos anos iniciais, preferiu realizar uma aula mais expositiva do que exploratória, o que gerou problemas no modo como direcionou suas ações e não conseguiu, em sua interação verbal com os alunos, permitir conexões entre a atividade lúdica anterior e a introdução da classificação de alguns sólidos geométricos na turma do $4 .^{\circ}$ ano.

As imagens das cenas discutidas retrataram uma experiência compartilhada que trouxe consigo elementos dessa supervalorização do professor, em detrimento da participação mais ativa do aluno. Sofia, à frente da sala, tentou fazer explicações utilizando como recurso a lousa e apresentação de alguns sólidos a partir de sua manipulação, mas não oportunizou aos alunos o acesso a nenhum tipo de material concreto que tivesse o objetivo de contribuir para o desenvolvimento da tarefa.

A análise dessa forma de conduzir a aula direcionou as professoras a contribuir com Sofia no sentido de explicitarem que ela poderia ter feito um trabalho mais exploratório em que a utilização de caixas, objetos semelhantes e diferentes serviriam de base para classificação e/ou planificação e isso poderia contribuir para a compreensão de aspectos da geometria espacial e plana.

Outros recursos a utilizar poderiam ainda ser embalagens de produtos e/ou recipientes que os próprios alunos teriam a oportunidade de coletar em casa e trazer à escola como forma de sistematização junto à professora no instante da aula. Pires, Curi e Campos (2000) reforçam que o uso desses materiais, a partir da exploração por parte dos alunos, pode leválos a representar graficamente e a planificar, dando origem a construções novas.

Para além dos recursos que poderiam ter sido recorridos por Sofia, caso tivesse acesso e conhecimento sobre, o objeto central da reflexão foram os equívocos conceituais nitidamente observados no vídeo. Conjecturamos que essas limitações conceituais em geometria são decorrentes, no Brasil, de uma reduzida formação matemática tanto na Educação Básica quanto no Curso Superior de Pedagogia - curso responsável pela formação inicial do professor que atua nos anos iniciais de escolarização. Esse histórico de formação profissional das professoras, ao mesmo tempo que reforça a necessidade de sua formação continuada, afeta e impacta os resultados obtidos por esta pesquisa em termos de aprendizagem docente e de desenvolvimento profissional em um contexto colaborativo.

Zetetiké, Campinas, SP, v.24, n.2, maio/ago.2016, p.249-268

ISSN 2176-1744 
http://periodicos.sbu.unicamp.br/ojs/index.php/zetetike

No ambiente de colaboração, por exemplo, decorrente do tempo e natureza das atividades feitas pelo grupo de professoras, o respeito mútuo e a valorização do saber de cada docente iniciante fez com que esse momento de análise crítica ocorresse de forma produtiva e permitiu uma autoanálise das práticas profissionais de cada uma das integrantes. Embora os vídeos que promoveram a reflexão sobre a formação das professoras tenham sido restritos aos de Alice e Sofia, isso não impediu que as demais reconhecessem que também tinham dificuldades semelhantes, tendo apontando, inclusive, aspectos comuns aos dois perfis de formação, no caso a Licenciatura em Matemática e o Curso de Pedagogia.

Em síntese, podemos concluir que a interação desencadeada nesses encontros de formação continuada levou à compreensão de que, na prática escolar, na maioria das vezes, o ensino da Geometria é "esquecido" ou omitido pelas práticas pedagógicas das professoras iniciantes devido ao fato de elas terem tido pouco estudo e experiência sobre esse tema durante seu percurso de formação. Tal constatação corrobora com os resultados da pesquisa de Fonseca et al. (2005, p. 23), quando afirmam que é comum "perceber que o conteúdo de geometria aparece sempre no final, dando a entender que é um estudo deixado para o fim do período letivo", situação que impede o acesso dos alunos a esse conhecimento fundamental e, consequentemente, de desenvolverem o pensamento geométrico.

O reconhecimento dessas dificuldades demonstra uma preocupação dessas jovens professoras em constituir uma prática profissional que contribua com a aprendizagem de seus alunos. Contudo, cumpre salientar que os equívocos conceituais não necessariamente são conscientes e de responsabilidade única dos docentes, mas, sim, de um processo histórico de formação com sérios problemas ligados, principalmente, a unidade conceitual da Matemática. Como indica Pavanello (1993), o ensino de Geometria é um campo abandonado, o que implica "a necessidade de investimentos em pesquisas sobre metodologias mais apropriadas para a abordagem desse conteúdo e em ações destinadas a proporcionar aos professores condições para a melhoria da qualidade desse ensino" (p. 16).

Nos dois casos analisados, constatou-se que as aulas das docentes estavam melhor embasadas no conhecimento didático em detrimento do conhecimento matemático, ou seja, as professoras iniciantes tinham mais domínio dos procedimentos didáticos ou metodológicos do que dos conhecimentos específicos do conteúdo (Ponte \& Chapman, 2008). Branco e Ponte (2011), além disso, argumentam que boas experiências em Didática da Matemática são importantes para o desenvolvimento indissociável entre o conhecimento matemático e o didático dos professores ou futuros professores.

A Matemática tem sido apresentada no curso de Pedagogia de forma fragmentada e essa constatação resulta em uma formação centrada em processos metodológicos de ensino, o que não tem contribuído para a formação específica dos acadêmicos (Curi, 2004). Com isso, a abordagem conceitual de Geometria e suas propriedades são raramente exploradas de forma adequada com os futuros professores.

Zambon (2010), ao discutir a Geometria sob a perspectiva da formação docente em sua dissertação de mestrado, expõe em uma análise dos objetivos propostos pelos Parâmetros 
http://periodicos.sbu.unicamp.br/ojs/index.php/zetetike

Curriculares Nacionais de Matemática (Brasil, 1998) que "não é objetivo para os anos iniciais fazer com que as crianças decorem nomes de figuras, mas, que explorem propriedades e diferentes formas de classificá-las" (p. 55). Mas, essa prática acaba ocorrendo cotidianamente em número considerável das práticas escolares investigadas em pesquisas anteriores, justamente pela precária formação em relação a essa área do currículo matemático (Nacarato, 2000; Nacarato \& Passos, 2003; Fonseca et al., 2005). Sendo assim, a formação matemática acaba reforçando a prática mecanizada baseada em procedimentos e memorização de técnicas, além da forte dependência do livro didático.

Como verificamos, o movimento produzido pela análise dos vídeos das aulas de Geometria permitiu que o grupo tomasse consciência da natureza de suas ações didáticas e o fato de se verem ministrando a aula tornou-se um dispositivo de autoavaliação importante para processos de ensino futuros em relação à Matemática, desencadeando um processo de "reflexão sobre a ação", como destaca Schön (1992).

Nacarato, Gomes e Grando (2008) consideram relevante compartilhar saberes em geometria, uma vez que

esse campo matemático raramente é trabalhado nas escolas públicas e, quando o é, ocorre ou ao final do ano ou de forma totalmente destituída de sentido e significado para o aluno. Isso sem dúvida, é decorrente das lacunas que o professor traz em sua formação quanto à Geometria (p. 27).

Tal como esses autores, verificamos, neste estudo, que a alternativa do trabalho colaborativo, envolvendo professores em um processo de estudo e reflexão, possibilita aos docentes atender seus anseios, compartilhar saberes e práticas de sala de aula e ampliar seus conhecimentos sobre eles, bem como promover uma participação mais efetiva dos alunos durante o processo de aprendizagem de conteúdos escolares, como é o caso da geometria.

\section{Conclusão}

A partir das características identificadas no perfil de trabalho com a geometria, expostos pela análise reflexiva dos vídeos de Alice e Sofia, a constituição do espaço de reflexão e colaboração, decorrente desses episódios, contribuiu para despertar questões orientadoras do trabalho futuro das professoras iniciantes como, por exemplo:

a) compreender que as aulas de Matemática, quando acompanhadas por reflexões, permitem ao professor tomar consciência de suas ações e rever posicionamentos, como também reconhecer a importância de propor tarefas de geometria mais exploratórias para os alunos;

b) perceber que o contato com as relações geométricas deve iniciar-se desde a Educação Infantil numa perspectiva de construção do espaço e percepção das formas;

c) identificar que os conceitos de geometria são representações mentais e, portanto, compete às tarefas propostas o papel de auxiliar na passagem do pensamento concreto para o abstrato; 
http://periodicos.sbu.unicamp.br/ojs/index.php/zetetike

d) considerando que a observação passiva proposta por Sofia não possibilitou aos alunos compreenderem as propriedades das formas geométricas, cabe ao docente criar contextos de manipulação, construção e percepção espacial de modo abrangente;

e) verificar que o objetivo do ensino desse bloco de conteúdo precisa desenvolver-se baseado na percepção e organização do espaço em que os alunos vivem.

Com base nessas conclusões, a problemática refletida no grupo se inseriu ainda na constatação de que existem dificuldades no trabalho pedagógico com a geometria nos primeiros anos de escolarização, as quais são decorrentes do processo de escolarização das participantes como da formação inicial em cursos de Pedagogia.

Desse modo, mais do que descrever e expor os problemas e perspectivas de atuação, a experiência de assistir o vídeo da aula e analisar cenas do processo de ensino e aprendizagem permitiu ao grupo propor e tentar buscar caminhos teórico-metodológicos de forma reflexiva "com" as professoras de modo a contribuir para a constituição do ser educadora matemática, principalmente, relação à sua aprendizagem em geometria para habilitarem-se a ensinar os conteúdos previstos ao ano escolar em que atuavam. O uso do vídeo, como forma de problematização da prática pedagógica, constitui um recurso que deve ser mais explorado nos grupos colaborativos e precisa ser melhor investigado por pesquisas futuras.

Nessa perspectiva, acreditamos que é relevante em um contexto formativo com características colaborativas, como foi o caso da experiência de formação continuada descrita e analisada nesse artigo, identificar, problematizar e tratar as demandas e dificuldades conceituais e didáticas das professoras, evidenciadas a partir dos vídeos das aulas compartilhadas.

Por fim, essa experiência despertou a necessidade e reforçou o pressuposto de que é preciso ampliar a discussão inicial acerca da formação em geometria dos professores no contexto em que eles contextualizam e ressignificam esses saberes, ou seja, na própria prática de trabalho diário na escola, quando do momento de sua inserção na docência, prática essa possível no grupo colaborativo investigado por nós.

\section{Referências}

Bogdan, R. \& Biklen, S. (1994). Investigação qualitativa em educação: uma introdução à teoria e aos métodos. (pp.47-51). Porto, Porto Editora.

Branco, N. C. V. (2013). O desenvolvimento do pensamento algébrico na formação inicial de professores dos primeiros anos. Tese (Doutoramento em Educação, Didática da Matemática), Instituto de Educação - Universidade de Lisboa.

Branco, N. C. V. \& Ponte, J. P. da. (2011). A álgebra na formação inicial de professores dos primeiros anos: Uma experiência de formação. Disponível em: http://repositorio.ul.pt/bitstream/10451/4570/1/Branco\%2c\%20Ponte\%20ID\%203\%2 81\%29\%202011.pdf. Retirado em: 02/mar.2016.

Zetetiké, Campinas, SP, v.24, n.2, maio/ago.2016, p.249-268

ISSN 2176-1744 
http://periodicos.sbu.unicamp.br/ojs/index.php/zetetike

Brasil. Ministério da Educação e do Desporto. (1998). Secretaria de Educação Fundamental. Referencial Curricular Nacional para a Educação Infantil. Vol. 3.Brasília: MEC/SEF.

. Ministério da Educação. (1997). Secretaria de Educação Fundamental. Parâmetros Curriculares Nacionais: Matemática ( $1^{\circ}$ e $2^{\circ}$ ciclos do ensino fundamental). v. 3. Brasília: MEC.

. Ministério da Educação. Conselho Nacional de Educação. (2001). Parecer CNE/CES 1.302/2001. Diretrizes Curriculares Nacionais para os Cursos de Matemática, Bacharelado e Licenciatura, 06 de novembro de 2001. Retirado em 30 de março, 2014, de: <http://portal.mec.gov.br/cne/arquivos/pdf/CES13022.pdf>,

Ciríaco, K. T. (2016). Professoras iniciantes e o aprender a ensinar Matemática em um grupo colaborativo. Tese (Doutorado em Educação), Faculdade de Ciências e Tecnologia - Universidade Estadual Paulista 'Júlio de Mesquita Filho' (FCT/UNESP).

Curi, E. (2004). Formação de professores polivalentes: uma análise de conhecimentos para ensinar Matemática e de crenças e atitudes que interferem na constituição desses conhecimentos. Tese de Doutorado em Educação Matemática, Pontifícia Universidade Católica de São Paulo. PUC/SP.

. (2011). A formação inicial de professores para ensinar Matemática: algumas reflexões, desafios e perspectivas. In: REMATEC: Revista de Matemática, Ensino e Cultura, 6 (9), 75-94.

Fiorentini, D. \& Oliveira, A.T.C.C. (2013). O Lugar das Matemáticas na Licenciatura em Matemática: que matemáticas e que práticas formativas? Bolema, 27 (47), 917-938.

Fonseca, M.C, Lopes, M.P, Barbosa, M.G.G., Gomes, M.L.M. \& Dayrell, M.M.M.S.S. (2005). O ensino de Geometria na Escola Fundamental: três questões para a formação do professor dos ciclos iniciais. Belo Horizonte: Autêntica.

Franco, M. A. R. S. (2005). Pedagogia da Pesquisa-ação. Educação e Pesquisa, v. 31, n. 3, set./dez. 2005, São Paulo. Retirado em 05 de outubro, 2013, de: $\langle$ http://www.scielo.br/pdf/ep/v31n3/a11v31n3.pdf $>$.

Freire, P. (1996). Pedagogia da autonomia: saberes necessários à prática educativa. São Paulo: Paz e Terra.

Fullan, M. \& Hargreaves, A. (2000). A escola como organização aprendente: buscando uma educação de qualidade. 2. ed. Porto Alegre: Artes Médicas.

Gálvez, G. A. (1996). Geometria, a psicogênese das noções espaciais e o ensino da Geometria na escola primária. In Parra, C.; Saiz, I. (Orgs.). Didática da Matemática: reflexões psicopedagógicas. (pp. 236-258). Tradução por Juan Acuña Llorens. Porto Alegre: Artes Médicas. 
http://periodicos.sbu.unicamp.br/ojs/index.php/zetetike

Grando, R. C. (2000). O conhecimento matemático e o uso dos jogos na sala de aula. Tese (Doutorado em Educação), Universidade Estadual de Campinas. Faculdade de Educação, UNICAMP.

Guarnieri, M. R. (1996). Tornando-se professor: o início na carreira docente e a consolidação da profissão. Tese (Doutorado em Educação). Universidade Federal de São Carlos: UFSCar.

Kamii, C. (1990). A criança e o número. Campinas: Papirus.

Marcelo García, C. (1999). Formação de Professores: Para uma mudança educativa. Portugal: Porto Editora.

Moura, M. O. (2001). A atividade de ensino como ação formadora. In Castro, A; CARVALHO, A (orgs). Ensinar a ensinar: didática para a escola. São Paulo: Editora Pioneira.

Nacarato, A. M., Gomes, A. A. M. \& Grando, R. C. (2008). Experiência com geometria na escola básica. São Carlos: Pedro \& João Editores.

Nacarato, A. M. (2000). Educação continuada sob a perspectiva da pesquisa-ação: currículo em ação de um grupo de professoras ao aprender ensinando geometria. Tese (Doutorado em Educação), Faculdade de Educação, Universidade Estadual de Campinas - UNICAMP.

Nacarato, A. M. \& Passos, C. L. B. (2003). A Geometria nas séries inicias: uma análise sob a perspectiva da prática pedagógica e da formação de professores. São Carlos: Edufscar.

Nono, M. A. (2011). Professores iniciantes: o papel da escola em sua formação. Porto Alegre: Mediação.

Panizza, M. A direita... de quem? Localização espacial na educação inicial e nas séries iniciais. (2006). In Panizza, M. (org.). Ensinar Matemática na Educação Infantil e nas Séries Iniciais: análise e propostas. (pp. 143-167). Porto Alegre: Artes Médicas.

Pavanello, R. M. (1993). O abandono do ensino de geometria no Brasil: causas e conseqüências. Revista Zetetiké, 2 (1), 7-17.

Pires, C. M. C., Curi, E. \& Campos, M. M. (2000). Espaço e forma: a construção de noções geométricas pelas crianças das quatro séries iniciais do Ensino Fundamental. São Paulo: PROEM.

Ponte, J. P. \& Chapman, O. (2008). Preservice mathematics teachers' knowledge and development. In L. English (Ed.). Handbook of international research in mathematics education. (pp. 225-263). New York, NY: Routldge.

Santaló, L. A. (1996). Matemática para não-matemáticos. In: SAIZ, I.; PARRA, C. (Orgs.). Didática da Matemática: reflexões psicopedagógicas. (pp. 11-25). Porto Alegre: Artes Médicas. 
http://periodicos.sbu.unicamp.br/ojs/index.php/zetetike

Schön, D. A. (1992). Designing as reflective conversation with the materials of a design situation. Knowledge-Based Systems, 5(1), 3-14.

Vasconcellos, M. (2005). Figuras geométricas não-planas e planas: a aprendizagem dos alunos da $4^{a}$ série e as concepções dos seus professores. Dissertação (Mestrado em Educação), Universidade Católica Dom Bosco, UCDB.

Zambon, A. E. C. (2010). A geometria em cursos de pedagogia da região de Presidente Prudente-SP. Dissertação (Mestrado em Educação), Universidade Faculdade de Ciências e Tecnologia de Presidente Prudente - FCT/UNESP. Presidente Prudente/SP.

Submetido em: 02/06/2016

Aceito em: 20/07/2016 